DESIGN AND REFORM OF TAXATION POLICY 


\section{FINANCIAL AND MONETARY POLICY STUDIES}

Volume 25

The titles published in this series are listed at the end of this volume. 


\title{
DESIGN AND REFORM OF TAXATION POLICY
}

\author{
Edited by \\ G. GALEOTTI \\ Università di Perugia \\ and \\ M. MARRELLI \\ Università di Napoli
}

SPRINGER-SCIENCE+BUSINESS MEDIA, B.V. 
Library of Congress Cataloging-in-Publication Data

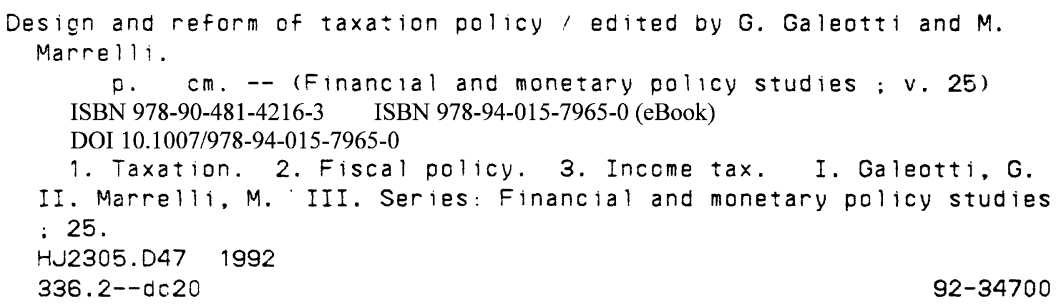

Printed on acid-free paper

All Rights Reserved

(C) 1992 Springer Science+Business Media Dordrecht

Originally published by Kluwer Academic Publishers in 1992

Softcover reprint of the hardcover 1st edition 1992

No part of the material protected by this copyright notice may be reproduced or utilized in any form or by any means, electronic or mechanical, including photocopying, recording or by any information storage and retrieval system, without written permission from the copyright owner. 


\section{TABLE OF CONTENTS}

Introduction

Part I. Tax Design and Reform: Theoretical Issues

F. Bukkaen

The Theory of Commodity Tax Reform: A Survey

$V$. Dardanoni

The Fiscal System and the Dynamic Redistribution of Income

R. Martina

The Effects of Uncertain Tax Policies on the Behaviour of Firms

B. Quintieri and C. Rosati

Demographic Changes, Public Savings and Tax Policies

\section{Part II. Non Marginal Tax Reforms}

A. Fossati, B. Cavaletti and A. Pench

From Personal to Indirect Taxation: A general equilibrium approach

V. Visco

Fiscal System and Fiscal Reform in Italy in the 90s

F. Stroffolini

Welfare Effects of Tax Progressivity

R. Levaggi

Fiscal Autonomy, Grants-in-Aid and Expenditure of Local Government 


\title{
Introduction
}

\author{
G. Galeotti* and M. Marrelli** \\ *Università di Perugia **Università di Napoli
}

1. The economic analysis of optimal taxation has permitted considerable steps to be taken towards the understanding of a number of problems: the appropriate degree of progression, the balance between different taxes, the equity-efficiency trade-off etc.. Though at times considered as abstract and of little use in policy design, the issues it addresses are real ones and very much on the agenda of many countries.

As usual in scientific debate, criticisms have contributed to the correct understanding of the theoretical problems involved and made clear that, at the present state of the art, definitive conclusions may be premature. A first well-taken criticism addresses the assumption, underlying optimal taxation models, of a competitive economy with perfect information on the part of individual agents and full market clearing. Once we leave the Arrow-Debreu world, it is no longer necessarily the case that taxes and transfers introduce distortions on otherwise efficient allocations.

A second reservation concerns the assumed absence of transaction costs and of institutional and political constraints. The economic analysis of politics has made important contributions in stressing the context within which political decisions are made. In this framework two levels of decisions making are relevant: a higher level constitutional choice, where a number of consensus criteria should apply, such as justice, social welfare and individual freedom, and a lower level, where fiscal variables are determined by the political machinery. It follows that analytical models of optimal taxation have to incorporate the notion that policy objectives cannot be simply interpreted in terms of social welfare function based solely on individual welfare.

However, much of the theory of optimal taxation is based on the implicit assumption of institutional or political constraints; the basic tenet of this theory is that, in a perfectly competitive world, taxes distort behaviour and cause excess burden. There do exist nondistortionary taxes; the optimal tax problem embodies the assumption that such taxes are difficult to institute in practice. This is due either to an information problem or to a political or institutional constraint. Taxes on genetic characteristics associated with ability may be non-distortionary but they require an informational content that is not feasible and they are, anyway, proscribed by the political or constitutional setting.

At the same time, we cannot forget that the very notion of dead-weight costs of taxes, subsidies and other types of public action is based on the strong assumption that there are no behavioural relations between revenues and expenditures. If we accept the existence of a variety of behavioural bridges between benefits and costs, the effective dead-weight cost of government actions is likely to be less than the one illustrated in our textbooks. Suppose that tax rates change because of an institutional improvement that reduces politicians' or 
bureaucrats' degree of freedom. In this case the links between costs and benefits of public action become tighter and the marginal dead-weight cost of tax increase can fall.

The existence of transaction costs and the impact of social institutions have a bearing, also, on the theory of optimal tax reform.

The theory of optimal tax design is characterised by the fact that global optima are sought; in doing this, however, it overlooks the fact that an initial allocation often exists.

Even if a new tax system may be welfare preferred to an existing one, the effects of transition from old to new may be undesirable; in designing the tax reform it is necessary, therefore, to take account of these transition effects.

Moreover, in the analysis of tax reform, starting from an existing tax structure, the direction in which to move is not always evident. Even if all distortions can be somewhat reduced, this does not necessarily increase welfare: an increase in economic efficiency would occur only if we were, initially, sufficiently close to the global optimum.

Another related problem is that of piecemeal reforms, i.e. whether one can increase economic efficiency in a piecemeal fashion, by removing distortions one at the time; in general these reforms may reduce welfare along the transition path to a global optimum.

The theory of tax reform has stressed the fact that, in general, only small and piecemeal changes in the existing tax structure are feasible (due to transaction costs or institutional constraints) so that the emphasis has been shifted from the "second best" maximising logic of optimal tax theory to the "second best" improving logic of tax reforms. The pursuing of this less ambitious objective has somewhat produced more fruitful and simpler results.

Much remains to be done, however: the building of closer links between econometric estimations and policy implications of the results, the analysis of policy in a non ArrowDebreu framework, the bringing together of optimal taxation or reform and public choice in a two-stage decision making, and, finally, the analyses of many neglected issues like the resource costs of implementing different tax structures, the problem of demographic changes, the definition of inter-temporal equity and so on are all fields of interesting further research

Some of these issues are discussed in this volume, whose emphasis, as suggested by the title, is mainly on filling the still wide gap between theory and practice.

2. This book is divided into two sections: the first one deals mainly with theoretical issues, while the second tackles the problem of implementation of tax reforms with the main concern of evaluating possible tax reforms.

A survey of the theory of commodity tax reform is provided by Fabrizio Bulkaen's paper that examines the most recent contributions to the literature of "uniformity versus selectivity". Whether a departure from uniformity can increase social welfare, depends on the differences in the distributional characteristics of commodities but also, in the case of non-fixed labour supply, on the differences in the marginal propensity to pay taxes out of incremental income and on the differences in the compensated wage elasticities of demand for the taxed commodity. On the other hand, it seems that we have still to establish the 
possibility of obtaining some useful theoretical indications concerning the direction of desirable tax reforms in the case of differentiated tax rates' structures in the initial positions.

Much of the literature reviewed by Bulkaen deals with equity considerations that refer to "static" comparisons of income distributions. However, static inequality studies pay "excessive" attention to "snapshots" of the existing income distribution, while a better measure of the opportunities faced by the individuals should be based on lifetime earnings. The paper by Valentino Dardanoni considers two aspects of the dynamic welfare ranking of income distributions; on the one hand, it analyses the dynamic effects of the redistribution of income resulting from the operation of the fiscal system, and, on the other, it examines the effects of social mobility on social welfare. The aim of the paper is to present a simple algorithm, similar to the Lorenz curve ordering in the static case, which is able to rank different social mobility structures with respect to a class of Social Welfare Functions.

Another relevant reservation on the theory of tax reform concerns the lack of attention dedicated to the timing of reforms and the welfare effects of too many changes in the tax structure. The paper by Riccardo Martina tackles this problem; it is shown that the introduction of uncertainty on tax policies, either on effective tax rates or tax base, causes reactions in the strategy of risk-averse firms and reduces over-all welfare. This implies that tax reforms should not happen too often and that the tax system should be made as clear and as easy to comply with as possible.

In the final part of the first section of the volume, Beniamino Quintieri e Furio Rosati examine the problem of how demographic changes affect the structure of the tax system and which possible reforms are available in a world of decreasing and ageing population and its effects on savings and labour supply.

In the second section of the volume issues concerning the evaluation of possible tax reforms and their effects on relevant strategic variables are analysed.

The paper by Amedeo Fossati et al examines, by the use of a simulation model, the effects of a partial tax reform directed to shift a certain amount of revenue from direct to indirect taxation. The interest in the problem arises from the consideration that, because of narrow income tax bases and of high levels of avoidance, the tax on personal income cannot be considered anymore an efficient one. The results of this simulation are interesting: national income and tax revenue would increase, while total welfare loss would be almost zero.

Vincenzo Visco's paper examines the structure and the proposals of reform of the Italian fiscal system, furnishing an interesting account of the process with which decisions on fiscal reforms are made in Parliament. A complementary analysis is to be found in Francesca Stroffolini's paper, where different tax structures and proposals of reform are evaluated by the use of a Social Welfare Function that takes explicit account of the distribution of income. This class of S.W.F. is a recent contribution to economic theory and is equivalent to establishing an ethically founded social evaluation function for the index of inequality. In the paper an S.W.F. based on the mean income and the Gini coefficient is used.

Finally, the paper by Rosella Levaggi deals with the problem of local tax reforms and their implication for the traditional issue of local finance "autonomy vs. control"; the effects of 
alternative methods of financing local government are examined within an intertemporal life cycle model and the simulation results are discussed.

We are grateful to all those who, on both sides of the Atlantic, have so generously given their time as referees and have helped us in the difficult selection of the papers among the many good ones discussed in the 1990 meeting of the Italian Society of Public Economics. 